\title{
A constituiçấo do Eu em Merleau-Ponty e o estatuto DA PROJEÇÁ̃O NA PSICANÁLISE FREUdIANA ${ }^{1}$
}

\author{
Renato dos Santos $^{2}$
}

\begin{abstract}
Resumo: As reflexóes desenvolvidas ao longo do presente artigo se apresentam como desdobramento do texto de Alfredo Pereira Jr., mais especificamente sobre a noção de Eu sentiente e do conceito de "projeção", desde a psicanálise freudiana. Num primeiro momento, analisa-se de que forma Merleau-Ponty, em contraste com as filosofias empirista e racionalista, reformula a noção da subjetividade, num plano fenomenológico e ontológico. $\mathrm{O}$ Eu se define não mais por uma sorte de pensamento, ou por uma causalidade de leis físicas e químicas, mas pelo entrelaçamento na carnalidade do mundo. Em seguida, investiga-se a noçấo de projeção em Freud, a fim de evidenciar como tal conceito ocupa a função de "proteção" para o Eu. A projeção (de)limita o "lugar" necessário para que o Eu possa se desenvolver, conforme mecanismo de defesa. Por fim, sustenta-se que a noção de Eu merleau-pontyano e a projeção freudiana convergem, na medida em que ambas só podem ser pensadas como experiências dentro de um mundo de relações que ocorrem por uma dimensão inconsciente, aproximando-se, assim, com a proposta de Pereira Jr..
\end{abstract}

Palavras-chave: Eu sentiente. Carne. Merleau-Ponty. Projeção. Freud.

\section{INTRODUÇÁO}

As reflexôes que desenvolverei ao longo do presente artigo se apresentam como desdobramento do texto ${ }^{3}$ de Alfredo Pereira Jr., mais especifica-

${ }^{1}$ Este artigo foi escrito a convite do Dr. Alfredo Pereira Jr., para compor o número especial de 2018 da Revista Trans/Form/Ação dedicado ao tema "consciência". Registro, aqui, o meu agradecimento ao Professor Alfredo pelo convite para integrar o quadro de autores do número especial.

${ }^{2}$ Doutorando em Filosofia pela Pontifícia Universidade Católica do Paraná (PUCPR), Curitiba, PR - Brasil, e pela Universidade de Coimbra (UC), Coimbra - Portugal. E-mail: renatodossantos1@ hotmail.com

Bolsista CAPES. É autor do livro O quiasma do mundo: a questão da alteridade em Merleau-Ponty (Editora CRV, 2017).

3 Trata-se do artigo The projective theory of consciousness: from neuroscience to philosophical psychology, de Alfredo Pereira Jr., mais exatamente a partir da discussão da "figura 4".

http://dx.doi.org/10.1590/0101-3173.2018.v41esp.13.p243

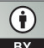

This is an open-access article distributed under the terms of the Creative Commons Attribution License. 
mente sobre a noção de "Eu sentiente" e do conceito de projeção, desde a psicanálise freudiana. Mostrarei como o estatuto de Eu é pensado por Merleau-Ponty, a partir de uma fenomenologia da percepção e de uma ontologia da carne; em seguida, apresento como a projeção, conforme desenvolvida por Freud, se configura enquanto mecanismo que faz função de proteção para o $\mathrm{Eu}^{4}$, em relação aquilo que lhe apresenta como algo estranho.

O estatuto de uma subjetividade, que é transparente a si mesmo, que detém o mundo ao poder de sua constituição, tem seu ápice na modernidade. Com Descartes, aprendemos que o Eu se define a partir de si mesmo, que ele, por um movimento metódico da razão, independe do mundo para constituirse. Aliás, é ele quem constitui o mundo e tudo o que nele existe. Na perspectiva da filosofia cartesiana, o Eu preexiste à experiência. Se o racionalismo fez da consciência o fundamento do conhecimento e tomou o Eu como absoluto, para o empirismo, não fugiu muito à regra. Ao considerar que o conhecimento tem sua origem nas sensaçôes, outorgou à consciência um lugar de mero receptáculo das informaçôes captadas. Fato é que, apesar disso, ainda é um Eu que opera e organiza essas informaçóes. Por esse motivo, a despeito das discordâncias entre as filosofias modernas, conforme Merleau-Ponty (1991, p. 168), figurava, como pano de fundo, a ideia de que "o ser da alma ou o sersujeito não é um ser menor, que talvez seja a forma absoluta do ser."

A implicação que uma filosofia fundada no sujeito proporciona, do ponto de vista ontológico, é a separação entre sujeito e objeto ou, conforme a expressão cartesiana, res cogitans e res extensa. Ou se existe como pensamento, como extensão, como ser ou como nada. Trata-se, noutras palavras, para essas filosofias, de desconsiderar o negativo, o inconsciente, o irracional. Ao contrário dessas perspectivas, mostrarei que a noção de $E u$ sentiente proposta por Alfredo Pereira Jr. aproxima-se do sentido que Merleau-Ponty concede a esse mesmo conceito, na medida em que, em ambos, busca-se superar o dualismo entre sujeito e objeto, consciência e natureza, favorecendo a encarnação do eu num corpo vivo ou, se quiser, corpo carnal.

\footnotetext{
${ }^{4}$ Usaremos a palavra "Eu", com "E" maiúsculo, quando nos referirmos às três instâncias descritas por Freud, a saber, "Eu, Isso e Supereu". Porém, nas citaçóes diretas, manteremos segundo consta na tradução da Imago, ou seja, Ego, Id e Superego.
} 


\section{A subjetividade encarnada em Merleau-Ponty}

As investigaçóes implementadas por Merleau-Ponty em suas primeiras obras - A estrutura do comportamento (1942) e Fenomenologia da percepçáo (1945) - revelaram que as dicotomias entre alma e corpo, como se pensou nas abordagens clássicas ${ }^{5}$, não dão conta de explicar a natureza do fenômeno da existência. Segundo Merleau-Ponty (2011, p. 268), "a atitude reflexiva purifica simultaneamente a noção comum do corpo e a da alma, definindo o corpo como uma soma de partes sem interior, e a alma como um ser inteiramente presente a si mesmo, sem distância." Reduzido o corpo a mero objeto, uma filosofia reflexiva considera o Eu como sendo pura independência. Instalam-se, assim, dois modos puros de existência: "Ou existe-se como coisa ou existe-se como consciência.” (MERLEAU-PONTY, 2011 p. 268).

A análise reflexiva exclui a ambiguidade do corpo, na medida em que realiza a separaçáo do que é da ordem do pensamento (atividade) e do que é da ordem da matéria (passividade). Ao passo que concebemos não mais tal separação entre espírito e corpo, passamos a compreender como a existência é marcada por uma ambiguidade fundamental. Se tomarmos como ponto de partida, de acordo com Merleau-Ponty (2011, p. 269), o fato de que não temos um corpo, mas somos um corpo, veremos que sexualidade, visão, motricidade, liberdade, por exemplo, "não podem estar ligadas entre si e ao mundo exterior por relaçôes de causalidade, todas elas estáo confusamente retomadas e implicadas num drama único."

Para Merleau-Ponty, não há como separar-se do corpo para se falar dele, retirar-se para o interior do pensamento, de modo a conseguir encontrar uma possível pureza da existência. Afinal, é necessário considerar que,

[q]uer se trate do corpo do outro ou de meu próprio corpo, não tenho outro meio de conhecer o corpo humano senáo vivê-lo, quer dizer, retomar por minha conta o drama que o transpassa e confundir-me com ele. Portanto, sou meu corpo, exatamente na medida em que tenho um saber adquirido e, reciprocamente, meu corpo é como um sujeito natural, como um esboço provisório de meu ser total. Assim, a experiência do corpo próprio opóe-se ao movimento reflexivo que destaca o objeto do sujeito e o sujeito do objeto, e que nos dá apenas o pensamento do corpo ou o

\footnotetext{
5 Por "abordagens clássicas", Merleau-Ponty se refere à fisiologia e à psicologia de caráter cognitivo comportamental, que tomam o corpo como objeto e separam a alma do mesmo - a clássica divisão entre o psíquico e o fisiológico. Sabemos, evidentemente, que atualmente muita coisa mudou em relação a essas perspectivas, muito embora ainda haja teóricos que buscam manter tal perspectiva, quando se trata a respeito do corpo e da alma, num âmbito da medicina, por exemplo.
} 
corpo em ideia, e não a experiência do corpo ou o corpo em realidade. (MERLEAU-PONTY, 2011, p. 269).

O corpo próprio furta-se da redução que a filosofia reflexiva faz dele, ou seja, como corpo objeto. Isso ocorre precisamente porque, na dimensão da experiência, o corpo se revela enquanto corpo-sujeito, como ser-no-mundo. O sujeito somente se constitui, na medida em que é corpo, suas relaçôes com os outros se dão unicamente pelo fato de que é figurado como corporeidade. Ser um corpo significa, noutras palavras, "estar atado a um certo mundo, e nosso corpo não está primeiramente no espaço: ele é no espaço" (MERLEAUPONTY, 2011, p. 205), ou ainda, "o corpo é um eu natural e como que o sujeito da percepção.” (MERLEAU-PONTY, 2011, p. 278).

Convém lembrar duas distinçôes conhecidas na tradição fenomenológica a respeito do corpo, ou seja, o corpo como Körper e Leib. O primeiro refere-se ao corpo da ciência, partes extra partes, ou, ainda, do ponto de vista da psicanálise, o corpo "real". O corpo como Leib, por outro lado, diz respeito ao corpo que acabamos de descrever, isto é, o corpo próprio - se se preferir, corpo simbólico. Em sua ontologia da carne, Merleau-Ponty levará às últimas consequências tal conceito, para pensar a natureza, o entrelaçamento do eu e do outro, do visível e do invisível. Mas isso veremos mais adiante. Por ora, importa esclarecer que náo se trata, para Merleau-Ponty, de ignorar o corpo da ciência (Körper), mas recusar a redução da totalidade do corpo apenas a essa perspectiva.

Assim, o corpo fenomenal "não é uma ideia, é um microfenômeno, o corpo objetivo é um microfenômeno. Mas a verificação só é obtida sob a condição de que se deixe de lado a noção de corpo-objeto e de espírito." (MERLEAU-PONTY, 2000, p. 348). Deixar de lado significa dizer que o corpo objetivo somente é possível porque, antes, há um corpo que percebe, que está ligado ao mundo não por uma relação de causalidade, mas de estrutura carnal reversível. É interessante recordar que o espírito e o corpo objeto não são fundadores do desejo. Entendo, aqui, por desejo, aquilo que faz com que o sujeito busque algo além de si mesmo, como identidade positiva. Somente uma subjetividade que é atravessada por uma falta, ou melhor, por um negativo, que detém a possibilidade de desejar. Conforme Merleau-Ponty (2000, p. 340), "um espírito não desejaria, assim como não perceberia. Qual é o Eu do desejo? É o corpo, evidentemente." 
O corpo é sujeito de movimento, pois é sujeito de desejo. Um sujeito cartesiano jamais desejaria, precisamente porque é um sujeito de positividade pura que detém a transparência do mundo por um ato de pensamento. Para desejar, é preciso ser furado, ser ultrapassado por um excesso de mundo e, ao mesmo tempo, ser um corpo encarnado no mundo. A respeito disso, vejamos a passagem em que Barbaras (2011, p. 158) comenta acerca do estatuto do desejo, desde uma fenomenologia da vida:

O desejo é a maneira específica pela qual o ser vivo se relaciona originariamente com uma exterioridade, é a forma primitiva e fundadora da intencionalidade. É enquanto desejo que a vida é capaz de dar origem a uma relaçáo com objetos e, portanto, é como desejo que a percepção se enraíza originariamente no ser vivo.

A gênese do desejo, como frisamos anteriormente, não reside num cogito, numa consciência constituinte. O desejo é da ordem do pré-reflexivo, de uma intencionalidade operante fundada no corpo próprio, e não de um ego transcendental. ${ }^{6}$ Interessante notar, ainda segundo Barbaras, a distinção entre "desejo" e "necessidade". Desejo não é vontade, tampouco necessidade. O que caracteriza o desejo é, justamente, o fato de que "o objeto que ele visa aviva-o no momento em que o preenche, de modo que a fonte de satisfação é ao mesmo tempo um motivo de insatisfação." (BARBARAS, 2011, p. 159). Assim, se o desejo é da ordem do originário, do corpo próprio, de uma intencionalidade corpórea, a vontade é do consciente, na medida em que ela é racionalizada e, quando satisfeita, ela cessa.

O desejo, por sua vez, é por natureza da ordem do impossível, da insatisfaçáo, precisamente porque o sujeito é ontologicamente incompleto. Esgotar o desejo (no sentido de satisfação plena) é aniquilar o sujeito, uma vez que "o ser vivo é caracterizado por uma insatisfaçâo que, por definição, não pode ser superada já que ele visa uma totalidade impossível, já que a aparição do objeto da sua ânsia equivale à sua desaparição enquanto sujeito." (BARBARAS, 2011, p. 158).

\footnotetext{
${ }^{6}$ Sobre isso, assevera Merleau-Ponty (2011, p. 217): "A percepção erótica não é uma cogitatio que visa um cogitatum; através de um corpo, ela visa um outro corpo, ela se faz no mundo e nâo em uma consciência. [...] Há uma "compreensão" erótica que não é da ordem do entendimento, já que o entendimento compreende percebendo uma experiência sob uma ideia, enquanto o desejo compreende cegamente, ligando um corpo a um corpo."
} 
Com efeito, falar de desejo, como vimos, é falar de algo que caracteriza o ser humano como algo que o faz mover. Destacamos, a partir de Merleau-Ponty, que o Eu do desejo é o corpo, o qual é definido como corpo sujeito. Diante disso, cabe esclarecer qual é o estatuto desse sujeito, isto é, como ele é estruturado. Desde suas primeiras obras, o filósofo procurou uma dimensão que antecede o pensamento, uma dimensão originária na qual nossa existência se apoia, um estofo primordial. Na Fenomenologia da percepção, Merleau-Ponty reencontra como sustentaçáo da existência um cogito pré-reflexivo, inconsciente. Aliás, nas palavras do filósofo, era esse cogito

\begin{abstract}
[s]ilencioso que Descartes visava ao escrever as Meditaçôes, ele animava e dirigia todas as operaçôes de expressão que, por definição, sempre erram seu alvo já que elas interpóem, entre a existência de Descartes e o conhecimento que dela ele adquire, toda a espessura das aquisiçóes culturais, mas que não seriam nem mesmo tentadas se em primeiro lugar Descartes não tivesse uma visão de sua existência. (MERLEAU-PONTY, 2011, p. 539).
\end{abstract}

O cogito tácito é, portanto, essa experiência que o sujeito detém enquanto ser no mundo. Esse cogito, porém, não constitui o mundo, mas tão somente percebe as doaçóes de sentido que o mundo o proporciona. A condição de possibilidade de todo conhecimento depende dessa dimensão que antecede qualquer pensamento constituinte da realidade. Nas palavras de Merleau-Ponty (2011, p. 541), essa subjetividade indeclinável não determina o mundo, senão "adivinha-o em torno de si como um campo que ela não se deu; ela não constitui a palavra, ela fala assim como se canta porque se está feliz; ela náo constitui o sentido da palavra, este brota para ela em seu comércio com o mundo e com os outros homens que o habitam.”

A consciência se instala com base na constituição sensível do sujeito. Quero dizer: ela é uma espécie de desdobramento da estrutura do Eu carnal. Nas palavras de Merleau-Ponty (2000, p. 340): "A consciência é sobrevoo." Ela opera a partir da tese do mundo, e não pelo próprio mundo em si. Tal é o cogito cartesiano, por exemplo. Para Merleau-Ponty (2011), o verdadei-

7 É nessa consciência, por exemplo, que a ciência moderna se apoia para realizar suas experiências: "A ciência manipula as coisas e renuncia habitá-las. Estabelece modelos internos delas e, operando sobre esses índices ou variáveis as transformaçôes permitidas por sua definiçẫo, só de longe em longe se confronta com o mundo real. Ela é, sempre foi, esse pensamento admiravelmente ativo, engenhoso, desenvolto, esse parti pris de tratar todo ser como 'objeto em geral', isto é, ao mesmo tempo como se ele nada fosse para nós e estivesse, no entanto, predestinado aos nossos artifícios.” (MERLEAU-PONTY, 2013, p. 15). 
ro cogito deve, necessariamente, considerar o enraizamento da consciência no mundo, isto é, "não é o face a face do pensamento com o pensamento deste pensamento: eles só se encontram através do mundo." (MERLEAU-PONTY, 2011, p. 400).

Nesse ponto, convém fazer menção ao texto de Alfredo Pereira Jr., The projective theory of consciousness: from neuroscience to philosophical psychology, mais precisamente no que se refere à noção de Eu sentiente como sendo uma das fases do fluxo da consciência. Considerando que esse conceito opera por uma dimensão pré-reflexiva, isto é, que se dá por um corpo, ele pressupõe que sua relação com o mundo não seja de constituição, mas de adesão à experiência fenomenológica. Assim, o Eu sentiente pode ser compreendido como sendo aquele Eu que não se define pela posse de si, por um ato de pensamento, mas se assenta nisso que Merleau-Ponty chama de pré-objetivo.

Se, por um lado, a consciência, ou o Eu cartesiano, somente exprime o que fora vivenciado numa dimensão tácita, por outro lado, esse inconsciente apenas se exprime por conta desse lado consciente. O que temos, aqui, são duas instâncias que estruturam a subjetividade, isto é, cogito pré-reflexivo e reflexivo, inconsciente e consciente. $\mathrm{O}$ funcionamento dessas duas dimensóes se dá por uma espécie de circularidade - dialética ${ }^{8}$-, na medida em que o fundo negativo da existência do sujeito depende dessa positividade para fazer-se aparecer.

O negativo, como lembra Merleau-Ponty (2011, p. 541), somente se "conhece nas situaçóes-limite em que está ameaçado: por exemplo, na angústia da morte ou na angústia do olhar de outrem sobre mim.” Isso não significa que o consciente seja fundante do inconsciente, desse negativo, mas que sua manifestação é reconhecida pela consciência como algo que escapa ao seu poder

\footnotetext{
${ }^{8} \mathrm{Na}$ Fenomenologia do espírito, mais exatamente na parábola do "senhor e o escravo", Hegel já antecipou a ideia de estrutura da subjetividade humana, que pode ser lida por uma lente ontológica, política e moral. Isto é, a tensão necessária que encontramos em tal dialética serve para explicar tanto o estatuto da subjetividade humana quanto a própria organização político-social da vida humana. A referida parábola descreve a relação entre senhor e escravo, ou a consciência dependente e independente. Escreve Hegel: "A dissolução daquela unidade simples é o resultado da primeira experiência; mediante essa experiência se põem uma pura consciência-de-si, e uma consciência que não é puramente para si, mas para um outro, isto é, como consciência essente, ou consciência na figura da coisidade. São essenciais ambos os momentos; porém como, de início, são desiguais e opostos, e ainda não resultou sua reflexão na unidade, assim os dois momentos são como duas figuras opostas da consciência: uma, a consciência independente para a qual o ser-para-si é a essência; outra, a consciência dependente para a qual a essência é a vida, ou o ser para outro. Uma é o senhor, outra é o escravo." Para saber mais, conferir o seguinte artigo de minha autoria (SANTOS, 2017a, p. 169-183).
} 
de vidência. É como se a consciência percebesse que ela não detém o poder absoluto de comandar a existência. Para usar uma expressão freudiana, equivale a afirmar que "o ego não é senhor da sua própria casa." (FREUD, 1996h, p. 153). As determinaçóes do inconsciente se apresentam como ilógicas frente à positividade da razão. É por esse motivo que afirmamos, no início deste parágrafo, com as palavras de Merleau-Ponty, que o cogito tácito exprime-se por si mesmo, embora seu conteúdo seja reconhecido pela consciência como aquilo que escapa. No texto de 1915, chamado $O$ inconsciente, ao dissertar acerca da justificação do estatuto do inconsciente, Freud afirma: "Todos os atos e manifestaçôes que noto em mim mesmo, e que não sei como ligar ao resto de minha vida mental, devem ser julgados como se pertencessem a outrem." (FREUD, 1996g, p. 175).

Esse "outrem" que o psicanalista descreve é, precisamente, o inconsciente, como se dentro de mim existisse um outro eu que manifesta comportamentos. Garcia-Roza (2009, p. 172) comenta que esse outrem "é o sujeito do inconsciente, do qual temos algumas indicaçóes seguras se nos voltarmos para os fenômenos lacunares." Tais fenômenos lacunares dizem respeito, por exemplo, ao sonho, ao lapso, ao ato falho, ao chiste e a outros sintomas que escapam de uma interpretação físico-psíquica das abordagens clássicas da ciência. Assim, o que podemos "captar" desse outrem, tomado como inconsciente, são fenômenos que se doam à experiência do sujeito consciente, produzindo uma espécie de passividade, visto que esses fenômenos, como já comentamos, se apresentam como "sem sentido" (non-sense).

É nessa direção que Merleau-Ponty aborda a relação com outrem, estranho ou, se se preferir, o Unheimliche freudiano. Sobre isso, enfatiza o filósofo:

Ocorre que, em certos espetáculos - os outros corpos humanos e, por extensão, os animais -, o meu olhar esbarra, é seduzido. Sou investido por eles enquanto julgava investi-los, e vejo desenhar-se no espaço uma figura que desperta e convoca as possibilidades do meu próprio corpo como se se tratasse de gestos ou comportamentos meus. Tudo se passa como se as funçóes da intencionalidade e do objeto intencional se encontrassem paradoxalmente trocadas. O espetáculo convida-me a tornar-me seu espectador adequado, como se um outro espírito que náo o meu viesse repentinamente habitar meu corpo, ou antes, como se meu espírito fosse atraído para lá e emigrasse para o espetáculo que estava concedendo a si mesmo. Sou apanhado por um segundo eu mesmo fora de mim, percebo o outro. (MERLEAU-PONTY, 1991, p. 100-101). 
Diante de outrem, o eu encontra-se passivo, como se um outro habitasse seus comportamos e expressasse significaçóes que ele náo buscou. $\mathrm{Ou}$, ainda, como se "os olhares que eu lançava pelo mundo como o cego tateia os objetos com o seu bastão, alguém os pegou pela outra ponta e os retorna contra mim para, por sua vez, tocar-me.” (MERLEAU-PONTY, 2012, p. 220). Semelhante ao inconsciente, esse outro é produtor de sentido e habita meu próprio mundo, sem que eu possa localizá-lo objetivamente.

É por conta dessa dimensão inconsciente, podemos dizer, que faz sentido tratar de desejo, outrem, identificação, alienação e do próprio eu. É por meio do outro que o eu encontra sua contrapartida necessária para constituir-se. Só é possível falar em identificação com aquele que ao mesmo tempo é semelhante e diferente de mim. Tanto para Merleau-Ponty quanto para a psicanálise, o outro ocupa um lugar fundamental na constituição do sujeito. Na Fenomenologia da percepção, Merleau-Ponty dá o exemplo acerca da relação da criança com sua mãe, mostrando como os gestos do corpo desse outro têm, para a criança, uma significação intersubjetiva, o que reforça a presença de um outro.

Um bebê de quinze meses abre a boca se por brincadeira ponho um de seus dedos entre meus dentes e faço menção de mordê-lo. E, todavia, ele quase não olhou seu rosto em um espelho, seus dentes não se parecem com os meus. Isso ocorre porque sua própria boca e seus dentes, tais como ele os sente do interior, são para ele imediatamente aparelhos para morder, e porque minha mandíbula, tal como ele a vê do exterior, é para ele imediatamente capaz das mesmas intençôes. A "mordida" tem para ele imediatamente uma significação intersubjetiva. Ele percebe suas intençóes em seu corpo, com o seu corpo percebe o meu, e através disso percebe em seu corpo as minhas intençóes. As correlaçóes observadas entre minhas mímicas e as de outrem, minhas intenções e minhas mímicas, podem fornecer um fio condutor no conhecimento metódico de outrem e quando a percepção direta fracassa, mas elas não me ensinam a existência de outrem. (MERLEAU-PONTY, 2011, p. 471-472).

É em função da imagem do outro - Grande Outro, diria a psicanálise lacaniana -, que a criança encontra suas primeiras referências para constituirse enquanto sujeito. Podemos sustentar que o eu surge sempre como uma resposta ao outro, no sentido de que é pela presença do outro que o eu poderá se diferenciar e ser sujeito: "Só sentimos que existimos depois de já ter entrado em contato com os outros, e nossa reflexão é sempre um retorno a nós mesmos, 
que, aliás, deve muito à nossa frequentação do outro.” (MERLEAU-PONTY, 2004, p. 48).

Isso somente se faz possível, vale lembrar, porque deixamos de lado a ideia de que o corpo do outro é mero objeto, e que o sujeito se constitui pelo poder da sua própria consciência. O corpo é gênese de significação. É a partir dele que podemos afirmar que existimos, enquanto sujeito de significação. Neste ponto, podemos entender o corpo próprio de Merleau-Ponty como o corpo simbólico da psicanálise, na medida em que é ele o portador de significação: "O corpo do outro, com suas diversas gesticulações, lhe aparece de imediato investido de uma significação emocional, é assim que ele aprende a conhecer o espírito, tanto como comportamento visível quanto na intimidade de seu próprio espírito." (MERLEAU-PONTY, 2004, p. 48).

Quando, na relação com o outro, o bebê percebe gestos e significaçóes que implicarão o reconhecimento de seu próprio corpo, o que ocorre nada mais é do que o desencadear de um circuito e a inserção desse bebê numa cadeia significante, a qual é possível por intermédio de sua existência corpórea. ${ }^{9}$ Segundo Merleau-Ponty (2004, p. 49), "nosso contato conosco sempre se faz por meio de uma cultura, pelo menos por meio de uma linguagem que recebemos de fora e que nos orienta para o conhecimento de nós mesmos." De fato, o sujeito só se realiza "por meio de uma linguagem e participando da vida no mundo.” (MERLEAU-PONTY, 2004, p. 49).

Com efeito, resta-nos esclarecer o fio condutor que nos fez chegar até aqui. Considerando o Eu sentiente, conforme desenvolvido por Alfredo Pereira Jr., buscamos verticalizar tal conceito na filosofia de Merleau-Ponty, mostrando como o filósofo radicaliza a noção de eu, subjetividade, do ponto de vista de sua encarnação no mundo. Partimos do pressuposto de que a subjetividade, as noçóes de corpo, outro, desejo, inconsciente, libido, projeção, introjeção, identificação etc. se tornam possíveis de análise, uma vez que não há espaço para estes do ponto de vista de uma subjetividade de natureza cartesiana, segundo mostramos anteriormente.

Em seu texto inacabado, $O$ visivel e o invisivel, Merleau-Ponty utiliza o conceito de sentiente para mostrar, precisamente, que o corpo é, ao mesmo

9 "É meu corpo como interposto entre o que está diante de mim e o que está atrás de mim, o meu corpo levantado diante das coisas levantadas, em circuito com o mundo - Einfühlung com o mundo, com as coisas, com os animais, com os outros corpos (como tendo também um 'lado' perceptivo), compreensível por essa teoria da carne." (MERLEAU-PONTY, 2000, p. 338). 
tempo, aquele que sente e aquele que é sentido. Em suas palavras MerleauPonty afirma que:

Há um círculo do palpado e do palpante, o palpado apreende o palpante; há um círculo do visível e do vidente, o vidente não existe sem existência visível; há até mesmo inscrição do palpante no visível, do vidente no tangível e reciprocamente; há, enfim, propagação dessas trocas para todos os corpos do mesmo tipo e do mesmo estilo que vejo e toco - e isso pela fundamental fissão ou segregação do sentiente e do sensível, que, lateralmente, faz os órgãos de meu corpo entrarem em comunicação, fundando a transitividade de um corpo a outro. (MERLEAU-PONTY, 2014, p. 139)

O corpo configura por excelência a carnalidade do eu, o qual é, agora, encarnado no mundo. Não mais atividade desprendida de passividade, senão passividade antes de atividade. Quer dizer, a atividade somente se realiza e é possível, porque há antes uma passividade frente ao mistério do mundo. Enquanto carne, o corpo se relaciona com as coisas, por meio de uma espécie de "narcisismo fundamental" ${ }^{10}$, uma vez que a carne do mundo e das coisas que o compóem são da mesma estrutura, mesma natureza: "o mundo e os outros tornam-se nossa carne.” (MERLEAU-PONTY, 2000, p. 341). Assim, “a carne do corpo nos faz compreender a carne do mundo. Encontramos o correlativo na natureza sensível (ser estatístico, macrofenômeno), é o corpo senciente.” (MERLEAU-PONTY, 2000, p. 351).

Interessante notarmos que Merleau-Ponty, como leitor da psicanálise, traz a psicanálise para pensar justamente a noção de carne, visto que tal conceito, aos olhos do filósofo, já se fazia presente na própria obra freudiana ${ }^{11}$ : "A filosofia de Freud não é uma filosofia do corpo, mas da carne." Para Merleau-Ponty (2014, p. 242):

\footnotetext{
10 "O meu esquema corporal como animal de condutas vive a distância no vivente exterior. Há entre eles uma relação carnal, uma extensão do narcisismo do corpo. Esse narcisismo é também abertura à generalidade: vivo como meus os comportamentos oferecidos e vejo-os animados por um esquema corporal. [...] é porque percebo que outrem é possível para mim como um outro que percebe os mesmos sensíveis que eu percebo. [...] O meu esquema corporal projeta-se nos outros e os introjeta, tem relaçóes de ser com eles, procura a identificação, apresenta-se como indiviso com eles, deseja-os." (MERLEAU-PONTY, 2000, p. 360-361).

${ }^{11}$ Em várias obras de Merleau-Ponty, pode-se constatar a presença da psicanálise freudiana. Em $O$ visivel e o invisivel, o filósofo chega a afirmar que "uma filosofia da carne é a condição sem a qual a psicanálise permanece antropologia.” (MERLEAU-PONTY, 2014, p. 240)
} 
Toda a arquitetura das noções da psico-logia (percepção, ideia - afeição, prazer, desejo, amor, Eros) se ilumina quando se pensa em termos de diferenciaçôes de uma única e maciça adesão ao ser que é a carne [...] porque não existe hierarquias de ordens ou de camadas ou planos, (sempre fundada sobre a distinção indivíduo-essência), existe dimensionalidade de todo fato e facticidade de toda dimensão - isso em virtude da "diferença ontológica." (Grifo do autor).

Merleau-Ponty vai mais longe, a ponto de afirmar que o corpo enquanto carne e como poder de "Einfühlung já é desejo, libido, projeção - introjeção, identificação - a estrutura estesiológica do corpo humano é, portanto, uma estrutura libidinal, a percepção um modo de desejo, uma relação de ser e não de conhecimento." (MERLEAU-PONTY, 2000, p. 340).

É este o ponto no qual acreditamos poder fazer a convergência entre a noção de Eu sentiente, enquanto corpo carnal, com a noção de projeção em Freud, porque o próprio Merleau-Ponty, como realçamos no parágrafo anterior, recoloca a projeção, identificação, introjeção etc., como entrelaçamento carnal e que, portanto, só é possível falar, na própria psicanálise, da ideia de projeção, porque há um corpo, há uma relação estabelecida entre o meu corpo e o corpo do outro. Noutros termos, não há como pensar em projeção, se não tivermos como pressuposto o entrelaçamento entre o inconsciente, $\mathrm{o} e u$ e o outro. Assim, a noção de indivisão carnal, de acordo com Merleau-Ponty, nos guiará para lermos o conceito de projeção na psicanálise, em especial na psicanálise freudiana.

\section{O CONCEITO de PROJEÇÃo EM Freud}

O conceito de "projeção" aparece pela primeira vez na obra de Freud, em 1895, num texto intitulado "Rascunho $H$ ", em anexo à carta endereçada a Wilhelm Fliess, e que tem por objetivo investigar a noção de "paranoia". ${ }^{12}$ No referido texto, Freud (1996a, p. 256) afirma que "o propósito da paranoia é rechaçar uma ideia que é incompatível com o Eu, projetando seu conteúdo no mundo exterior." Acrescenta:

\footnotetext{
${ }^{12}$ No texto Observaçôes adicionais sobre as neuropsicoses de defesa, de 1896, Freud (1996b, p. 174) define a paranoia nos seguintes termos: "Por tempo considerável tenho alimentado a suspeita de que também a paranoia - ou algumas classes de casos que se incluem na categoria de paranoia - é uma psicose de defesa; isto é, que, tal como a histeria e as obsessôes, ela provém do recalcamento de lembranças aflitivas, sendo seus sintomas formalmente determinados pelo conteúdo do que foi recalcado."
} 
Sempre que ocorre uma modificação interna, temos a opção de supor a existência de uma causa interna ou de uma causa externa. Quando algo nos impede a derivação interna, naturalmente recorremos à externa. E, depois, estamos acostumados a verificar que nossos estados internos se revelam (por uma expressão da emoçáo) às outras pessoas. Isso responde pelos delírios normais de estar sendo observado e pela projeção normal. Pois são normais na medida em que, nesse processo, permanecemos conscientes de nossa própria mudança interna. Se a esquecermos e se nos ativermos tão-somente a uma das premissas do silogismo, àquela que conduz para o exterior, teremos aí a paranoia, com sua supervalorização daquilo que as pessoas sabem a nosso respeito e daquilo que as pessoas nos fizeram. O que é que as pessoas sabem a nosso respeito, de que nada sabemos e que não podemos admitir? Trata-se, pois, de um abuso do mecanismo da projeçâo para fins de defesa. (FREUD, 1996a, p. 256, grifo do autor).

Tendo em vista as passagens anteriores, podemos entender que a projeção é um mecanismo de defesa do Eu, responsável por expelir tudo aquilo que se apresenta a ele como ameaça. Importante frisar que esse mecanismo não é operado por um processo de consciência, mas justamente inconsciente. Como lembra Grotstein (1985, p. 117), a projeção configura-se, portanto, como um "mecanismo mental pelo qual o self vivencia a fantasia inconsciente de translocar-se ou translocar aspectos de si mesmo para um objeto, para fins exploratórios ou defensivos."

A projeção desempenha a função de uma "proteção" ao Eu, na sua relação com um objeto ou com as outras pessoas. Um ano depois do texto sobre a paranoia, em 1895, Freud retoma o tema, em 1896, em Observaçóes adicionais sobre as neuropsicoses de defesa, e escreve o seguinte:

$\mathrm{Na}$ paranoia, a autoacusação é recalcada por um processo que se pode descrever como projeção. É recalcada pela formaçáo do sintoma defensivo de desconfiança nas outras pessoas. Dessa maneira, o sujeito deixa de reconhecer a autoacusaçáo; e, como que para compensar isso, fica privado de proteçáo contra as autoacusaçóes que retornam em suas representaçôes delirantes. (FREUD, 1996b, p. 182).

Assim, a projeçáo faz com que o sujeito coloque para fora aquele conteúdo que o Eu reconhece como ameaça. Uma determinada situação que o sujeito vivencia e que lhe causou uma espécie de trauma fará com que o Eu projete 
um conteúdo, um sentimento inverso daquele recalcado nos seus semelhantes ou em algo que o faça recordar aquela situação. O clássico caso de Freud sobre Schreber ilustra, com precisão, isso que estamos analisando. Não é a intenção nossa descrever o caso minuciosamente, com a riqueza de seus detalhes, todavia, entender o mesmo e pontuar a paranoia e, mais exatamente, a projeção.

Os delírios iniciais de Schreber eram de perseguição, já que se deu a transferência com seu médico neuropsiquiatra, Dr. Flechsig, pelo qual Schreber possuía desejos homossexuais e lutava, conscientemente, contra esses desejos. Segundo Freud (1998, p. 73), o que há de caracteristicamente "paranoico na doença foi o fato de o paciente, para repelir uma fantasia de desejo homossexual, ter reagido precisamente com delírios de perseguição desta espécie." As formulaçóes que ilustram essas transformaçóes paranoicas de amor em ódio, bem como da projeçáo, são descritas por Freud (1998, p. 77-78) da seguinte maneira:

$$
\begin{aligned}
& \text { "Eu (um homem) o amo" é contraditada por: } \\
& \text { Delírios de perseguição, pois eles ruidosamente asseveram: } \\
& \text { "Eu não o amo - Eu o odeio." }
\end{aligned}
$$

Interessante recordar que essas frases enunciadas no plano inconsciente jamais serão ditas conscientemente por um paranoico, uma vez que "o mecanismo de formaçáo de sintomas na paranoia exige que as percepçóes internas sentimentos - sejam substituídas por percepçóes externas.” (FREUD, 1998, p. 78). Nesse sentido, "a proposição 'eu o odeio' transforma-se, por projeção, em outra: Ele me odeia (persegue), o que me desculpará por odiá-lo.” (FREUD, 1998, p. 78). Como comentamos anteriormente, o Eu projeta para o exterior justamente o contrário daquilo que está escrito no inconsciente.

Em outras palavras, quando Schreber afirma que seu médico o persegue - "Eu não o amo - eu o odeio, porque ELE ME PERSEGUE" (FREUD, 1998, p. 78) - e que o odeia, na verdade, o que está afirmando é que ele (Schreber) o ama, quer dizer, "o perseguidor é alguém que foi outrora amado." (FREUD, 1998, p. 78). O mecanismo de projeção se encarrega, por conseguinte, de evitar que o Eu se depare com a verdade que lhe é íntima, inconsciente. A título de exemplo acerca da projeção, e ainda no âmbito do amor recalcado, podemos pensar em uma mulher que exala ódio para a pessoa que outrora era seu companheiro e pela qual nutria um grande amor, e hoje o odeia com a mesma intensidade como o amava. Em tal situação, a partir dos exemplos anteriores, 
podemos inferir que o ódio que ela exala conscientemente é, na verdade, uma negação do amor que ainda se mantém no inconsciente.

Ressalta Freud (1998, p. 81):

A característica mais notável da formação de sintomas na paranoia é o processo que merece o nome de projeçāo. Uma percepção interna é suprimida e, ao invés, seu conteúdo, após sofrer certo tipo de deformação, ingressa na consciência sob a forma de percepção externa. Nos delírios de perseguição, a deformação consiste numa transformação do afeto; o que deveria ter sido sentido internamente como amor é percebido externamente como ódio.

O que fora recalcado retorna para o sujeito por uma percepção em uma aparência inversa daquele conteúdo. É como se o sujeito se defrontasse com o que é de si próprio, no seu semelhante, sem saber que, na verdade, isso que ele percebe é dele mesmo, pois esse processo escapa à sua simbolização. Isto é, o que o sujeito recalcou reaparece, por intermédio da projeção, enquanto real para si. Ocorre que o Eu se depara com aquilo que até entáo não estava à sua vista, contudo, se mantinha nas profundezas do inconsciente. A percepção de algo externo, como destaca Freud, é responsável por revelar ao sujeito seus próprios fantasmas. No exemplo específico da paranoia de Schreber, na qual o Eu recalcou os desejos homossexuais, Freud considera que o que está na base dessa enfermidade é, precisamente, a homossexualidade. ${ }^{13}$ Por esse motivo, Schreber teve reaçóes delirantes de perseguição em relação a seu médico, pois o que ela visava a evitar era o desejo recalcado.

Poderíamos estender esse raciocínio para tentarmos compreender, por exemplo, a situação político-social que atravessa o Brasil, mais exatamente do ódio deflagrado por algumas pessoas às diferenças, a grupos que escapam de uma (hetero)normatividade aceitável na sociedade. Tornou-se comum ouvirmos frases que exclamam odiosamente o retorno de gays, negros, mulheres etc., para a margem do esquecimento, os quais deixassem de protagonizar na sociedade como começaram a fazer desde alguns anos para cá, através de direitos conquistados. Há, agora, um esforço em afirmar uma identidade rigorosa que se apresenta como modelo a ser seguido moralmente, desconsiderando outros modos de existência.

13 "Estas consideraçôes emprestam, portanto, peso adicional à circunstância de que somos, na realidade, levados pela experiência a atribuir às fantasias de desejo homossexuais uma relação íntima (talvez invariável) com essa forma específica de enfermidade." (FREUD, 1998, p. 73). 
Entretanto, o que esse cenário de ódio às diferenças evidencia, seguindo as considerações de Freud, é uma inversão do afeto que foi recalcado. De maneira mais específica em relação aos homossexuais - contra quem é tão gritante o ódio, em nossa sociedade -, o que se revela é um desejo por outra pessoa do mesmo sexo, por parte daquele que odeia homossexuais, uma vez que o sujeito que vive sua homossexualidade conscientemente causa naquele que a recalcou um desconforto, pois o que este deseja inconscientemente é poder viver isso que fora recalcado. Trata-se, portanto, do fenômeno da projeçáo, já que sujeito projeta o afeto inverso do qual realmente sente, mas que está recalcado. ${ }^{14}$

Com efeito, no que concerne ao tema da projeção, na psicanálise freudiana, convém analisar o desdobramento do conceito em suas obras seguintes, como, por exemplo, no texto de 1913, chamado Totem e tabu. Nesse texto, Freud escreve o seguinte:

A projeção da hostilidade inconsciente sobre os demônios, no caso do tabu relativo aos mortos, é apenas um exemplo de um certo número de processos aos quais se deve atribuir a maior importância na formaçáo da mente primitiva. No caso de que estivemos tratando, a projeção serviu ao objetivo de manejar um conflito emocional, sendo empregada da mesma maneira num grande número de situaçôes psíquicas que conduzem às neuroses. Mas a projeção não foi criada com o propósito de defesa; ela também ocorre onde não há conflito. A projeção de percepções internas para fora é um mecanismo primitivo, ao qual, por exemplo, estão sujeitas nossas percepçóes sensoriais, e que, assim, normalmente desempenha um papel muito grande na determinaçáo da forma que toma nosso mundo exterior. Sob condições cuja natureza não foi ainda suficientemente estabelecida, as percepçóes internas de processos emocionais e de pensamento podem ser projetadas para o exterior da mesma maneira que as percepçóes sensoriais. Sáo assim empregadas para construir o mundo externo, embora devam, por direito, permanecer sendo parte do mundo interno. Isto pode ter alguma vinculação genética com o fato de que a função da atenção se dirigia originalmente não no sentido do mundo interno, mas no dos estímulos que afluem do mundo externo e que as únicas informaçóes dessa função

\footnotetext{
${ }^{14} \mathrm{O}$ recalque é uma percepção retida que se nega a tornar-se passado, impedindo o sujeito de viver o tempo presente e projetar-se no futuro. O comentário de Merleau-Ponty (2011, p. 123) acerca do membro fantasma ilustra bem a noçáo de recalque, pois "o sujeito permanece sempre aberto ao mesmo futuro impossível, senão em seus pensamentos explícitos, pelo menos em seu ser efetivo.” Assim, o recalque faz com que o sujeito fique preso àquele passado que năo passa nunca, na medida em que fica sempre retornando no presente e impede a abertura para o futuro: "o sujeito se empenha em uma certa via - relação amorosa, carreira, obra —, encontra uma barreira nessa via e, não tendo força nem para transpor o obstáculo nem para renunciar ao empreendimento, permanece bloqueado nessa tentativa e emprega indefinidamente suas forças em renová-la em espírito." (MERLEAU-PONTY, 2011, p. 123).
} 
sobre os processos endopsíquicos era recebida a partir de sentimentos de prazer e desprazer. (FREUD, 1996c, p. 77).

Nessa passagem, Freud acrescenta uma outra conotação para a noção de projeção, isto é, a projeção não é um mecanismo que se faz presente apenas na paranoia, mas também em sujeitos normais, pois ela cumpre a função de formar imagens do mundo externo. Conforme já salientamos anteriormente, a projeção, grosso modo, pode ser definida como um mecanismo de defesa para o Eu. Dessa forma, consoante com a ideia expressa em Totem e tabu, podemos inferir que o Eu necessita construir no mundo exterior imagens, uma vez que esse mundo também se lhe apresenta como uma ameaça.

Em Os instintos e suas vicissitudes, de 1915, o psicanalista evidencia como o Eu divide o mundo entre o que é prazer e o que é desprazer, à proporçáo que ele introjeta o que se aproxima ao prazer, ao que náo lhe causa ameaça, e repele, pela projeção, o que é desprazer, ou que lhe soa como estranho. Noutros termos, os objetos que são fonte de prazer o Eu os introjeta, enquanto os que sáo fonte de desprazer ele os expele, projetando-os para o mundo exterior. ${ }^{15}$ Assinala Freud (1996f, p. 141):

$\mathrm{O}$ "ego da realidade", original, que distinguiu o interno e o externo por meio de um sólido critério objetivo se transforma num "ego do prazer" purificado, que coloca a característica do prazer acima de todas as outras. Para o ego do prazer, o mundo externo está dividido numa parte que é agradável, que ele incorporou a si mesmo, e num remanescente que lhe é estranho. Isolou uma parte do seu próprio eu, que projeta no mundo externo e sente como hostil. Após esse novo arranjo, as duas polaridades coincidem mais uma vez: o sujeito do ego coincide com o prazer, e o mundo externo com o desprazer (com o que anteriormente era indiferente).

Afirmar que o Eu sente prazer não significa que é o mesmo prazer do inconsciente, do Isso, uma vez que, para este, o prazer é desmedido, sem barreiras, desprovido de puniçôes. O prazer de que se trata no Eu diz respeito à objetividade que ele realiza das forças conflituosas que residem na estrutura do sujeito, ou seja, o prazer consiste justamente em manter o funcionamento

\footnotetext{
15 "Se o objeto for uma fonte de sensaçôes desagradáveis, há uma ânsia (urge) que se esforça por aumentar a distância entre o objeto e o ego, e a repetir em relação ao objeto a tentativa original de fuga do mundo externo com sua emissão de estímulos. Sentimos a 'repulsão' do objeto, e o odiamos; esse ódio pode depois intensificar-se ao ponto de uma inclinação agressiva contra o objeto - uma intenção de destruí-lo." (FREUD, 1996f, p. 141).
} 
do aparelho psíquico, o equilíbrio entre as determinaçóes do Isso e do Supereu. Aquilo que foi recalcado ou negado pelo Eu possui uma caricatura de ruim e, por esse motivo, suas percepçôes de algo externo com esse mesmo semblante lhe soam como assustador, maligno.

Em uma nota de rodapé, ainda em Totem e tabu, Freud (1996c, p. 78) afirma que "as criaçóes projetadas dos homens primitivos se assemelham às personificaçôes construídas pelos escritores criativos, porque os últimos externalizam sob a forma de indivíduos separados os impulsos instintivos opostos que lutam dentro deles." É como se o Eu projetasse para o exterior aquele conflito que existe internamente, pintando-os como imagens antagônicas, como, por exemplo, os espíritos e os demônios, os quais, para o psicanalista,

[s]ão apenas projeçốes dos próprios impulsos emocionais do homem. Ele transforma as suas catexias emocionais em pessoas, povoa o mundo com elas e enfrenta os seus processos mentais internos novamente fora de si próprio - exatamente da mesma maneira como aquele inteligente paranoico, Schreber, descobriu um reflexo das ligaçôes e dos desligamentos de sua libido nas vicissitudes de seus confabulados "raios de Deus". (FREUD, 1996c, p. 102).

Frente à tendência de sobreposição das determinaçốes, por parte do Supereu ou do Isso, a projeção se apresenta para o Eu como um mecanismo que faz a função de trazer-lhe uma espécie de alívio, diante da tensão causada pelo conflito entre os impulsos distintos:

Porque, evidentemente, eles não podem tornar-se todos onipotentes. $\mathrm{Na}$ realidade, o processo patológico na paranoia faz uso do mecanismo de projeção a fim de lidar com conflitos mentais dessa espécie. Caso típico de um conflito assim é que o que se dá entre dois membros de um par de opostos - o caso de uma atitude ambivalente, que examinamos em pormenores, no caso da pessoa que chora a morte de um parente amado. Esse tipo de caso parece ser particularmente passível de fornecer um motivo para a criação de projeçôes. Aqui, mais uma vez, estamos de acordo com os autores que sustentam que os primeiros espíritos a nascer foram os espíritos maus. Esses autores acham que a ideia de alma se derivou da impressão causada pela morte sobre os sobreviventes. (FREUD, 1996c, p. 102-103).

Aprofundando a questão da projeção das forças que conflituam no interior do sujeito, faz-se claro como Deus e o Diabo são criaçóes da mente 
humana com a mesma semelhança ${ }^{16}$ dos impulsos antagônicos que perpassam sua natureza ou, entáo, que a existência de espíritos maus e bons são, na verdade, uma extensão da experiência primitiva. Para Freud, Deus não é mais do que aquele que substitui o pai, quer dizer, ele é "um pai exalçado, ou, ainda, que constitui a cópia de um pai tal como este é visto e experimentado na infância - pelos indivíduos em sua própria infância, e pela humanidade em sua pré-história, como pai da horda primitiva e primeva." (FREUD, 1996d, p. 101). Assim, Deus é aquele pai protetor que vem amparar o sujeito em face de seu desamparo.

Todavia, tal como podemos observar em toda figura paterna, existe uma ambiguidade de sentimentos do filho para com o pai, isto é, não há para com o pai apenas "impulsos de natureza afetuosa e submissa, mas também impulsos hostis e desafiadores. É nossa opinião que a mesma ambivalência dirige as relaçôes da humanidade com sua Divindade." (FREUD, 1996d, p. 101). O Diabo não é de natureza distinta da de Deus, até porque o primeiro é antítese do segundo. Por esse motivo, aquele que hoje é considerado Deus poderá amanhã ser o Diabo: "Os deuses podem transformar-se em demônios maus quando novos deuses os expulsam. Quando determinado povo foi conquistado por outro, seus deuses caídos não raramente se transformam em demônios aos olhos dos conquistadores." (FREUD, 1996d, p. 101).

Curioso observar que essa mesma premissa é retomada por Freud, a fim de explicar o fenômeno do duplo, no texto de 1919, chamado O estranho (Das Unheimliche). Nele, o pai da psicanálise escreve:

A qualidade de estranheza só pode advir do fato de o "duplo" ser uma criação que data de um estádio mental muito primitivo, há muito superado - incidentalmente, um estádio em que o "duplo" tinha um aspecto mais amistoso. O "duplo" converteu-se num objeto de terror, tal como após o colapso da religião, os deuses se transformam em demônios. (FREUD, 1996e, p. 254).

\footnotetext{
${ }^{16}$ Ludwig Feuerbach (1804-1872) antecipou essa ideia em seu célebre livro A essência do cristianismo (1841). Para o filósofo, Deus foi criado à imagem e semelhança do homem, e não o contrário, como se pensou no cristianismo: "Deus é o interior revelado, o si-mesmo do homem expresso, a religiáo é o desvendamento festivo dos tesouros escondidos do homem, a confissão dos seus pensamentos mais íntimos, a proclamação pública dos seus segredos de amor." (FEUERBACH, 2002, p. 23). Ademais: "A essência absoluta do homem é a sua própria essência. O poder que o objecto tem sobre ele é, pois, o poder da sua própria essência." (FEUERBACH, 2002, p. 14). Em várias outras passagens, Feuerbach enfatiza a tese de que o homem projeta em Deus suas qualidades, o que pode ser aproximado com a tese freudiana acerca da criação de Deus por parte do homem.
} 
Conforme já comentei em outro texto ${ }^{17}$, o estranho é o que outrora era familiar, mas que, por um processo de recalcamento do Eu, tornou-se assustador. O estranho é, portanto, "aquela categoria do assustador que remete ao que é conhecido, de velho, e há muito familiar.” (FREUD, 1996e, p. 238). Assim como são projetados, em uma divindade, sentimentos bons e ruins, também o Eu projeta para fora o que há de estranho internamente nos seus semelhantes que prefiguram uma imagem estranha para ele.

Como escrevi anteriormente, quando me referi ao caso Schreber, mais especificamente ao ódio que ele exalava contra seu médico, também aqui podemos ler daquela maneira, através do mecanismo de projeção. Ocorre que, no fenômeno do duplo, o Eu projeta no externo o que ele recalca internamente: "na ânsia de defesa que levou o Eu a projetar para fora aquele material, como algo estranho a si mesmo." (FREUD, 1996e, p. 254). Mas isso que ele recalca retorna do exterior, por meio da percepção de um semblante disso que ele recalcou.

Assim como Schreber odiava seu médico por conta dos desejos homossexuais que sentia por ele, também podemos entender o ódio que vemos se intensificar cada vez mais em nossa sociedade, tal como, por exemplo, o ódio a negros, imigrantes e tantos outros. Em outras palavras, a gênese do ódio às diferenças está ligada diretamente a isso de estranho que o Eu recalcou dentro de si e, como ele avista, agora, a presença dessas pessoas com semblantes disso que foi recalcado, ele reage com comportamentos violentos.

Para finalizarmos o mapeamento do conceito de projeção, na obra freudiana, bem como sua funçấo na estrutura do sujeito, convém analisarmos a passagem a seguir, acerca do uso da projeçáo nos sonhos. No texto Suplementos metapsicológicos à teoria dos sonhos (1917), Freud define o sonho nos seguintes termos:

Um sonho nos diz que estava acontecendo alguma coisa que tendia a interromper o sono, e nos permite compreender de que maneira foi possível desviar essa interrupção. O resultado final é aquele que dorme, sonha e é capaz de continuar dormindo; a exigência interna que lutava por ocupá-lo foi substituída por uma experiência externa, cuja exigência foi eliminada. Um sonho é, portanto, entre outras coisas, uma proję̧ão: uma externalização de um processo interno.

\footnotetext{
${ }^{17}$ Refiro-me a um capítulo que escrevi aproximando a noção de outrem (autrui) em Merleau-Ponty com o conceito de Unheimliche de Freud, sob o título "O estranho familiar (Un-heimlich), ou a questáo da alteridade em Freud e Merleau-Ponty”. O texto encontra-se publicado no livro que coorganizei, intitulado Ontologia, política e psicanálise: discursos acerca da alteridade.
} 
Importante frisar que o sonho é uma manifestação do inconsciente, assim como os chistes e os atos falhos. Porém, no sonho, a projeção realiza a função de impedir que aquele conteúdo que fora projetado no sonho interrompa o sono. $\mathrm{O}$ desencadear da projeção ocorre no momento em que algo de estranho ameaça interromper o funcionamento do aparelho psíquico, possibilitando que o sujeito consiga conduzir sua existência normalmente. Isso que a projeção realiza, portanto, é simplesmente evitar que haja uma sobreposição dos impulsos do Isso, durante o estado de sono.

\section{CONSIDERAÇÓES Finais}

Quais conclusões podemos extrair das ideias de Merleau-Ponty e Freud, desenvolvidas ao longo do texto? O leitor provavelmente deve recordar que, na primeira seção, quando nos ocupamos em dissertar acerca da noçáo de Eu sentiente, em Merleau-Ponty, mostramos como a noção de eu é pensada pelo filósofo em termos de corporeidade, que o eu se constitui a partir da experiência no mundo. Segundo propusemos, no início do texto, a questão consiste em entender como a projeção, tal como desenvolve Freud, pode operar também nesse eu, conforme pensado em Merleau-Ponty, pois esse Eu sentiente a que estamos aludindo é perpassado por um fundo inconsciente, revelando, assim, o descentramento das subjetividades na carne do mundo. ${ }^{18}$

Num curso sobre a passividade, em 1954, Merleau-Ponty analisa a obra $A$ interpretação dos sonhos, a fim de mostrar como, no estado onírico, o sujeito é descentrado:

Existe, em $A$ interpretação dos sonhos de Freud, uma descrição completa da consciência onírica - uma consciência que ignora o nome, que não diz sim apenas tacitamente, produzindo diante do analista as respostas que ele espera dela, incapaz de fala, de cálculo e do pensamento atual, reduzida às elaboraçóes antigas do sujeito, para que nossos sonhos não

\footnotetext{
18 "O inconsciente evoca, à primeira vista, o lugar de uma dinâmica das pulsóes, da qual somente o resultado nos será dado. E, no entanto, o inconsciente nấo pode ser um processo 'em terceira pessoa', já que é ele quem escolhe o que de nós será admitido na existência oficial, que evita as situaçôes às quais nós resistimos e que não é, portanto, um não-saber, mas antes um saber não reconhecido, informulado, que nós não queremos assumir. Em uma linguagem aproximada, Freud está aqui a ponto de descobrir o que outros melhor nomearam de percepção ambigua. É trabalhando nesse sentido que se encontrará um estado civil para essa consciência que roça seus objetos, retira-os no momento em que vai pô-los, tem-nos em conta como o cego aos obstáculos, mais que não os reconhece, que não quer sabê-los, ignora-os enquanto os sabe, sabe-os enquanto os ignora e que sustenta por baixo nossos atos e conhecimentos expressos." (MERLEAU-PONTY, 1991, p. 259-260).
} 
sejam circunscritos à medida que os sonhamos e importamos em bloco para nossos atuais fragmentos inteiros de nossos momentos prévios - e essas descriçôes significam que o inconsciente é uma consciência perceptiva, procede como se faz através de uma lógica de implicação ou promiscuidade, e segue, passo a passo, um caminho onde náo há mais rendição total, visa objetos e seres através do negativo que ele detém, o que é suficiente para ordenar suas açóes, sem colocá-lo em posição de nomear "pelo nome". (MERLEAU-PONTY, 1968, p. 70-71).

O que o estado onírico revela é justamente a manifestação de um inconsciente e, mais do que isso, o fato de que o sujeito não é absoluto, de que ele é ultrapassado ou convivente com um fundo que se exprime nos seus comportamentos ou quando não está em estado de vigília. De acordo com Merleau-Ponty (1968, p. 178-198), o inconsciente é "o sentir mesmo, já que o sentir não é a possessão intelectual 'daquilo’ que é sentido, mas despossessão de nós mesmos em seu proveito, abertura àquilo que em nós é necessário pensar para compreender." Para sentir, para existir experiência no mundo fenomênico, é preciso que haja uma adesão do eu a esse mundo, mas uma adesão que não é abstrata, que não é uma determinação consciente.

Ao admitirmos que o eu náo é absoluto, mas encarnado, perpassado por um fundo inconsciente, admitimos também que a projeção, como mecanismo que opera inconscientemente na proteção do eu, pode ser pensada nesse contexto enquanto aquilo que vem confirmar a não absolutização do eu, revelando a presença de um outro lado. A projeção freudiana, nessa perspectiva, pode ser pensada, em termos merleau-pontyanos, como sendo da mesma natureza dos lapsos, dos chistes e do sonho. Noutras palavras, o que, de fato, tanto a projeção quanto esses outros fenômenos inconscientes revelam é a abertura possibilitada por esse inconsciente primordial que nos liga ao outro e à generalidade carnal.

Nessa direção, a projeção e a noção de Eu sentiente, a nosso ver, convergem para o que Alfredo Pereira Jr. desenvolve em seu texto, mais especificamente conforme está escrito na seguinte passagem:

O conceito de projeção foi proposto para explicar a geração dos sentidos do eu e do mundo, os dois pólos do campo informacional, sobre os quais a estrutura dinâmica da experiência consciente é construída. $\mathrm{O}$ domínio da experiência delimitado pelos dois pólos constitui um campo informacional fenomenal no 'espaço egocêntrico', tendo o ponto de vista subjetivo no centro e o mundo dos objetos como horizonte. (PEREIRA JR., 2018, p. 209). 
Segundo Pereira Jr. (2018), a projeção opera como um mecanismo que possibilita compreender como as sensações sentidas pelo eu são projetadas da experiência fenomenal, não como um sujeito cartesiano que constitui o mundo por uma representação, mas como encarnado num corpo carnal (Leib). A tese sobre a indivisão carnal de Merleau-Ponty nos ajuda a compreender a relação eu-mundo. Como vimos na primeira seção, entre o eu e o mundo não há separação objetiva, mas generalidade de estruturalidade carnal. Portanto, da mesma forma que Pereira Jr. se serve do conceito de Eu sentiente para dissolver a dicotomia sujeito-objeto, também Merleau-Ponty encontra nessa noção a sorte de superação da oposição consciência-natureza.

SANTOS, R. Merleau-Ponty's sentient Self and Freudian projection. Trans/Form/Açäo, Marília, v. 41, p. 243-268, 2018. Edição Especial.

\begin{abstract}
This article takes as its starting point a text by Alfredo Pereira Jr. which discusses MerleauPonty's notion of the sentient Self and the concept of "projection" in Freudian psychoanalysis. First we analyze how Merleau-Ponty, in contrast to empiricist and rationalist philosophies, reformulates the notion of subjectivity on a phenomenological and ontological plane. The Self is no longer defined by a kind of thought or by the causality of physical and chemical laws, but by its entanglement in the carnality of the world. Second, the notion of projection in Freud is investigated in order to show how this concept occupies the function of "protection" for the Self. Projection (de)limits the necessary "place" for the Self to develop. Finally, it is argued that Freud's concept of projection and MerleauPonty's notion of the Self converge, since both can only be thought of as experiences within a world of relations that occur in an unconscious dimension; it is in this sense that our proposal is similar to that of Pereira Jr.
\end{abstract}

KeYwords: Sentient Self. Flesh. Merleau-Ponty. Projection. Freud.

\title{
REFERÊNCIAS
}

BARBARAS, R. Investigaçōes fenomenológicas: em direção a uma fenomenologia da vida. Curitiba: Editora UFPR, 2011.

FEUERBACH, L. A essência do cristianismo. 2. ed. Lisboa: Fundação Calouste Gulbenkian, 2002.

FREUD, S. Rascunho H: Paranoia. In: - Obras psicológicas completas de Sigmund Freud: edição standard brasileira. Rio de Janeiro: Imago, 1996a. V. 1. (Original, 1895). 
- Observaçóes adicionais sobre as neuropsicoses de defesa. In: . Obras

psicológicas completas de Sigmund Freud: edição standard brasileira. Rio de Janeiro: Imago, 1996b. V. 3. (Original 1896).

. Totem e tabu. In: . Obras psicológicas completas de Sigmund Freud: edição standard brasileira. Rio de Janeiro: Imago, 1996c.V. 13. (Original 1913).

. Uma neurose demoníaca do século XVII. In: Obras psicológicas

completas de Sigmund Freud: edição standard brasileira. Rio de Janeiro: Imago, 1996d.V. 17. (Original 1923).

. O estranho. In: Obras psicológicas completas de Sigmund Freud: edição standard brasileira (Vol. XVII). Rio de Janeiro: Imago, 1996e. V. 17. (Original 1919).

. Os instintos e suas vicissitudes. In: . Obras psicológicas completas de Sigmund Freud: edição standard brasileira (Vol. XIV). Rio de Janeiro: Imago, 1996f. V. 14. (Original 1915).

O inconsciente. In: . Obras psicológicas completas de Sigmund Freud: edição standard brasileira. Rio de Janeiro: Imago, 1996g. V. 14. (Original 1915).

. Uma dificuldade no caminho da psicanálise. In: . Obras psicológicas completas de Sigmund Freud: edição standard brasileira. Rio de Janeiro: Imago, 1996h.V. 17. (Original 1917).

. Suplemento metapsicológico à teoria dos sonhos. In: Obras psicológicas completas de Sigmund Freud: edição standard brasileira, Rio de Janeiro: Imago, 1996i. (Original 1917).

O caso Schreber: notas psicanalíticas sobre um relato autobiográfico de um caso de paranóia (dementia paranoides). Rio de Janeiro: Imago, 1998.

GARCÍA-ROZA, L. A. Freud e o inconsciente. 24. ed. Rio de Janeiro: J. Zahar, 2009. GROTSTEIN, J. S. A divisão e a identificação projetiva. Rio de Janeiro: Imago, 1985. MERLEAU-PONTY, M. Résumés de cours. Collège de France (1952-1960). Paris: Gallimard, 1968. . Signos. São Paulo: Martins Fontes, 1991. . A natureza: Curso do Collège de France. São Paulo: Martins Fontes, 2000. . Conversas: 1948. São Paulo: Martins Fontes, 2004. . Fenomenologia da percepção. 4. ed. São Paulo: Martins Fontes, 2011. . A prosa do mundo. São Paulo: Cosac \& Naify, 2012. . O olho e o espirito. São Paulo: Cosac \& Naify, 2013. . O visivel e o invisivel. 4. ed. São Paulo: Perspectiva, 2014. 
MÜLLER-GRANZOTTO, M. J. Merleau-Ponty leitor de Freud. Natureza Humana, São Paulo, v. 7, n. 2, p. 399-432, dez. 2005.

PEREIRA JR., A. The projective theory of consciousness: from neuroscience to philosophical psychology. Tran/Form/Ação, v. 41, n. especial, 2018, 199-232.

SANTOS, R. A tensão necessária: notas sobre a relação entre o Eu e o outro em Hegel e em Merleau-Ponty. Prometeus. Filosofia em Revista, v. 10, n. 22, p. 169-183, jan./abr. 2017a. 2017 b.

. O quiasma do mundo: a questão da alteridade em Merleau-Ponty. Curitiba: CRV,

. O estranho familiar (Un-heimlich), ou a questão da alteridade em Freud e Merleau-Ponty. In: SANTOS, R.; GUTELVIL, L. (org.). Ontologia, politica e psicanálise: discursos acerca da alteridade. Porto Alegre: Editora Fi, 2018. p. 463-483. 
SANTOS, R. 